Print- ISSN: 1391-586X, E-ISSN: 2602-9030, Copyright @ 2019 by Faculty of Science, Eastern University, Sri Lanka.

\title{
HIGHLY FUNCTIONALIZED FIVE-MEMBERED BICYCLIC $\alpha$-HYDROXY ACIDS FROM SYNTHETIC EQUIVALENT OF GLYCOLIC ACIDS
}

\author{
Vajira P. Bulugahapitiya*
}

Department of Chemistry, Faculty of Science, University of Ruhuna, Matara, Sri Lanka.

\section{ABSTRACT}

Five-membered cyclic $\alpha$-hydroxy acids (1-hydroxycycycloalkane-1-carboxylic acids) are important constituents in biologically active natural products and also important precursor molecules for the synthesis of pharmacologically active compounds. This paper presents stereo selective synthesis of polysubstituted fivemembered bicyclic $\alpha$-hydroxy acid derivatives from $\alpha, \alpha$-dialkylated 1,3-dixolan4-one (9). The synthesis was initiated on the $\alpha$-propagylation of 2-(tert-butyl)-5(1-ethenylprop-2-enyl)-1, 3-dixololan-4-one (trans-8) via its enolate, followed by intramolecular Pauson-Khand cyclization. The reaction was stereo selective and afforded two isomers (10a and 10b) in 4:1 ratio out of four possible diastereoisomers of bicyclic $\alpha$-hydroxy acid (bicyclic 1-hydroxycarboxylic acid) derivatives. This method opens a new avenue to prepare synthetically useful highly functionalized stereoselctive synthesis of five-membered bicyclic $\alpha$ hydroxy acids using a convenient and very effective method.

Keywords: Stereoselctive synthesis, glycolic acids, five-membered bicyclic $\boldsymbol{\alpha}$ hydroxy acids, Pauson - Khand reaction,

*Corresponding author: vajira@ chem.ruh.ac.lk

(iD https://orcid.org/0000-0003-1178-1052 


\subsection{INTRODUCTION}

Cyclic $\alpha$-hydroxy carboxylic acids are important constituents in pharmacological active natural products and important synthetic building units for the synthesis of various biologically active natural products [1]. Although the research has mainly focused on the development of potential synthetic strategies for the synthesis of acyclic $\alpha$ - hydroxy acids [2], less attention has been paid on preparation of cyclic $\alpha$-hydroxy acids. Glycolic acids is an easily available, important $\alpha$-hydroxy acid which can be easily converted into the asymmetric acetals, and then it can serve as chiral auxiliaries in selective induction of its $\alpha$-position to prepare asymmetric 1-hydroxycycloalkane-1-carboxylic acid derivatives [3]. In our previous work, we reported stereo selective preparation of 1-hydroxycylclopentene-1-carboxylic acid derivatives (3, Figure 1) using chiral equivalent of glycolate derivatives via metathesis. This method has been successfully applied in the synthesis of natural product, (-)-quinic acid [4]. In another method, we have demonstrated synthesis of polysubstituted 1-hydroxyclyopentane-1-carboxylic acid derivatives (6a and $\mathbf{6 b}$, Figure 2) using chiral equivalent of glycolate derivatives via a group selective radical annulation procedure [5].

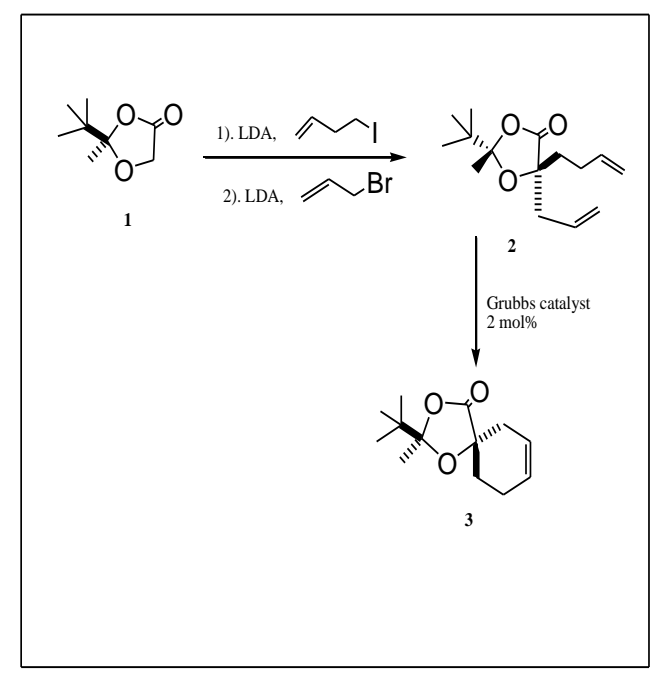

Figure 1: Synthesis of 1-

hydroxycycloalkene-1-carboxylic acid by Metathesis

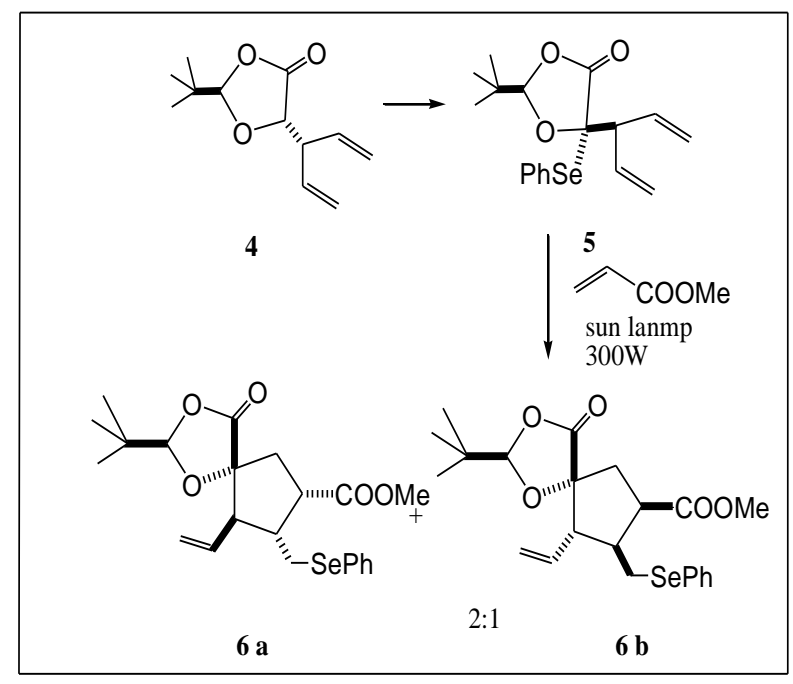

Figure 2: Synthesis of 1hydroxycycloalkene-1-carboxylic acid via radical annulation 
Development of synthetic strategies for the preparation of asymmetric bicyclic $\alpha$ hydroxy acids is equally important in organic synthesis. Pauson -Khand reaction has emerged as a convenient tool for the synthesis of cyclopentenones, from alkynes and alkene, involving of cobalt carbonyl compounds [6]. In this reaction, the alkyne first reacts with $\mathrm{Co}(\mathrm{CO})_{8}$ to form alkyne- $\mathrm{Co}_{2}(\mathrm{CO})_{6}$ complex and then it reacts with the alkene to form the cyclopentanone. We have planned a synthetic route to bicyclic 1-hydroxycarboxylic acid derivatives based on intramolecular Pauson-Khand cyclization of $\alpha, \alpha$-dialkylated glycolic acid derivatives. As a demonstration of the proposed method, we explain here the synthesis of asymmetric polysubstituted bicyclic 1-hydroxycarboxylic acids (10a and 10b, Figure-5) using glycolate derivatives synthesized via simple reactions process (Figure 3 \& 4).

\subsection{MATERIAL AND METHOD}

\subsection{General material and instruments used}

All the chemicals were purchased from Fluka, Switzerland. THF was freshly distilled in the presence of $\mathrm{K}$ under $\mathrm{N}_{2}, \mathrm{CH}_{2} \mathrm{Cl}_{2}$ was distilled in the presence of $\mathrm{CaH}_{2}$ under $\mathrm{N}_{2}$. Other reagents were obtained from commercial sources. For flash column chromatography: Merck silica gel 60 (70-230 mesh) and for TLC: Merck silica gel $25 \mathrm{~F}_{254}$, analytical plates were used. Detection either by UV, $\mathrm{I}_{2}$ or by spraying with phosphomolybdic acid solution, Diastereoselctivity was determined by means of GC; column Machenery-Nagel-OPTIMA-1701. Melting point was determined by Reicher Thermovar Kofler. IR spectra: PerkinElmermattson Unicam 50016PC FT-IR; NMR spectra: Varian Gemini 200 $\left({ }^{1} \mathrm{H}=200 \mathrm{MHz},{ }^{13} \mathrm{C}-50.3 \mathrm{MHz}\right)$;Bruker AM $360\left(1 \mathrm{H}=360 \mathrm{MHz},{ }^{13} \mathrm{C}=90.5 \mathrm{MHz}\right)$; Bruker Advance DRX $500\left({ }^{1} \mathrm{H}=500.13 \mathrm{MHz},{ }^{13} \mathrm{C}=125.8 \mathrm{MHz}\right)$, chemical shift in ppm relative to tetramethylsilane $(\delta=0) ; \operatorname{CDCl}_{3}(\delta=7.26 \mathrm{ppm})$ used as the solvent unless otherwise stated; Mass:Vaccum Generators Micromass VG70/70E; DS 11-250; EI (70 eV); CI $\left(\mathrm{CH}_{4}\right) ; \mathrm{m} / z(\%)$; FAB: matrix in 2nitrobenzylalcohol with $\mathrm{Ar}$ at $8 \mathrm{kV}$; IR in $\mathrm{cm}^{-1}$; Elemental analysis: Ilse Beetz, Microanalytisches Laboratorium, D-8640 Kronach, Germany. 


\subsection{Method}

The initial compound, ethyl 3-ethenyl-2-hydroxypent-4-enoate (7) to be used in the synthesis of precursor molecule for the targeted Pauson-Khand reaction, was prepared by the reaction of 5-bromo-1,3-pentadine with ethyl gloxylate with the presence of $\mathrm{Zn}$ powder and anhydrous $\mathrm{AlCl}_{3}$ (Figure 3) [7], [8]. This compound was then reacted with pivalaldehyde in the presence of acid catalyst to obtain 2(tert-butyl)-5-(1-ethenyl prop-2-enyl)-1,3-dixololan-4-one (8, Figure 3) [4]. The trans isomer of 8 ( $\alpha$-monosubstituted cyclic acetal of glycolate) which was obtained through column chromatographic purification of the mixture, was deprotonated with LDA in THF at $-78^{\circ} \mathrm{C}$ and then followed by alkylation with propagyl bromide to form $\alpha$-disubstituted cyclic acetal of glycolate (9, Figure 4), which was the substrate for the targeted Pauson-Khand cyclization.

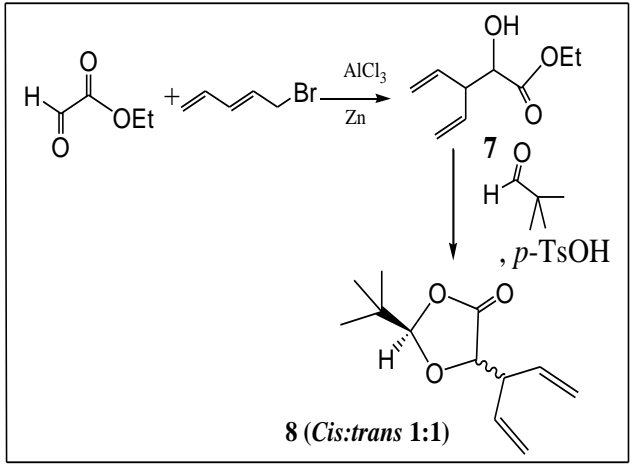

Figure 3 : Preparation of $\alpha$ monosubstituted cyclic acetal 2(tert-butyl)-5-(1-ethenyl prop-2enyl)-1,3-dixololan-4-one

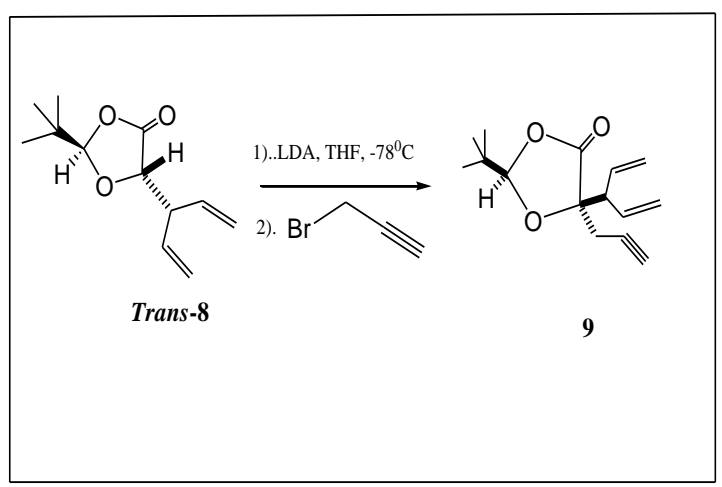

Figure 4 : Preparation of $\alpha$ disubstituted cyclic acetal, 2-acetal 2(tert-butyl)-5-(2-propynyl)-5-(1-vinyl2-propenyl)1,3-dioxoloan-4-one

At the next step, the compound 9 (2-tert-butyl-5-(2-propenyl)-5(1-vinyl-2-propenyl)1,3-dioxolan-4-one) was subjected to the intramolecular Pauson-Khand cyclization by reacting with cobalt carbonyl, $\mathrm{Co}_{2}(\mathrm{CO})_{8}$ at room temperature (r.t) followed by separation of the resultant alkyne- $\mathrm{Co}_{2}(\mathrm{CO})_{6}$ complex using flash chromatography, and then treating this complex with hydrated $\mathrm{N}$-methylmorpholine-N-oxide $\left(\mathrm{NMO} . \mathrm{H}_{2} \mathrm{O}\right)$ in $\mathrm{CH}_{2} \mathrm{Cl}_{2}$ at $\mathrm{r}$.t to form the desired bicyclic 1-hydroxycycarboxylic acid derivatives (Figure 5, 10a and 10b,) [9]. 


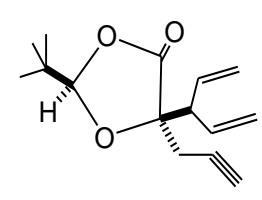

9
$\mathrm{CH}_{2} \mathrm{Cl}_{2}, \mathrm{rt}$

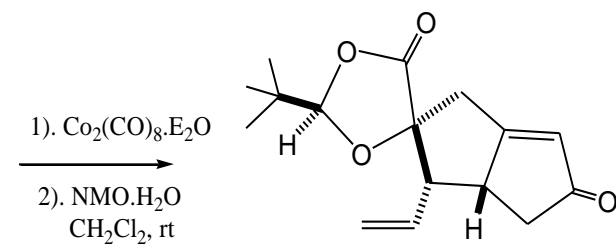

78: 22

10 a

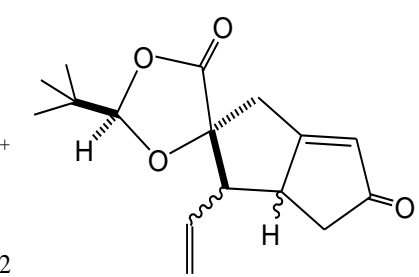

$10 \mathrm{~b}$

Figure 5: Intramolecular Pauson -Khand reaction to prepare bicyclic $\alpha$-hydroxyl acid derivatives

The stereo selectivity of the formed mixture of bicyclic 1-hydroxycarboxylic acid derivatives was analyzed with the help of gas chromatography and NMR spectroscopy. The mixture of isomers was separated using preparative HPLC and the structures of the diastereomers along with their relative stereochemistry were determined with the help of NMR studies (NOE difference spectra).

\subsection{RESULTS AND DISCUSSION}

The formation of ethyl 3-ethenyl-2-hydroxypent-4-enoate (7) was not stereo selective and it was formed as a racemic mixture in $52 \%$ yield in the reaction of nucleophilic addition of 5-bromo-1,3-pentadine to aldehyde carbonyl of ethyl gloxylate in the presence of $\mathrm{AlCl}_{3}$ (Figure 3). The cyclic acetal (8), 2-(tert-butyl)-5-(1-ethenyl prop-2enyl)-1,3-dixololan-4-one was formed as a 1:1 (cis:trans) mixture in $65 \%$ yield (Figure 3) and two isomers were successfully separable through column chromatography. The alkylation of the trans isomer of cyclic acetal, 8 with propagyl bromide was totally selective and afforded 2-(tert-butyl)-5-(2-propynyl)-5-(1-vinyl-2propenyl)-1,3-dioxoloan-4-one (9) in $65 \%$ yield (Figure 4). The total stereo selectivity in propagylation can be explained using the model given below (Figure 6). The enolate derived from the compound 8 should be in the preferable conformation as depicted in the Figure 6 and two vinyl groups are oriented in the way shielding of the two faces of the enolate equally and the propagylation is taken place anti to the tertbutyl group forming exclusively compound 9 [4], [10]. All the efforts made to alkylate the cis isomer were failed giving still no clear reasons. 


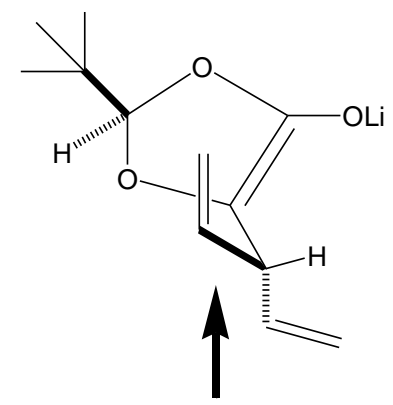

Figure 6: Stereo chemical model for the alkylation of Li-enolate derived from trans-8.

Pauson-Khand cyclization of the substrate compound 9 was highly selective and the desired bicyclic 1-hydroxycarboxylic acid derivatives (Figure 5, 10a and 10b) were formed as a mixture of two diastereomers (4:1) out of four possible diastereomers. This isomeric mixture could be separable only in preparative HPLC. The NOE different spectra supported to determine the relative stereochemistry of the major isomer, 7-[2tert-butyl)-6-vinyl-1,3'-dioxolan-4-noyl]-bicyclo [3.3.0] oct-1-en-3-one (10a) as shown below (Figure 7).

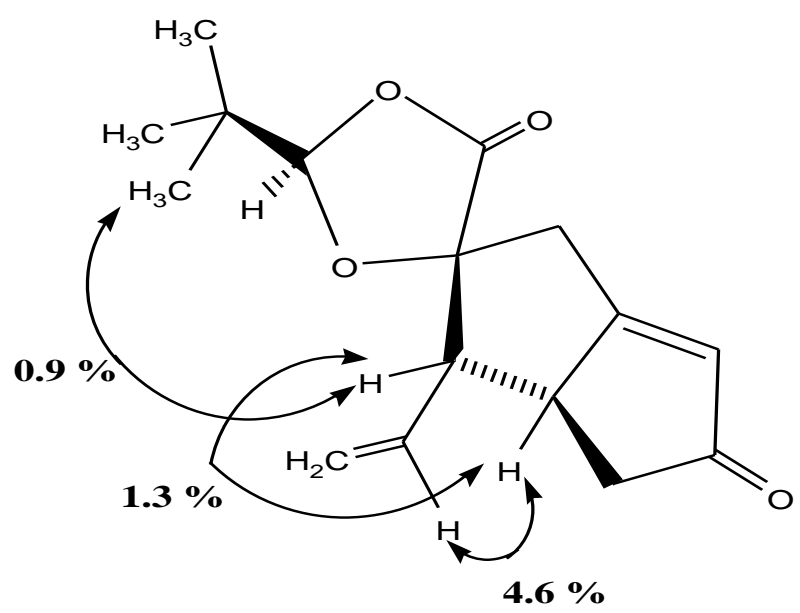

Figure 7: NOE's of major isomer, $\mathbf{1 0}$ a

The proposed mechanism for the intramolecular cyclization is given below (Figure 8). The stereo chemical outcome of the intramolecular Pauson-Khand cyclization could be rationalized by the formation of pseudo chair conformation of Cobolt-alkyne complex (A) with the orientation of one vinyl group at the equatorial position. The cyclization is mainly controlled by steric factors of tert-butyl group and cis-fused conformation is 
dominated with minimizing steric interactions between the vinyl group and the tertbutyl group in the intermediate. The metalocylce, $\mathbf{B}$ then undergo carbonyl insertion to form the intermediate $\mathbf{C}$, which is set up to migrate $\mathbf{C}$-Co bond to the adjacent electrophilic carbonyl carbon to form $\mathbf{D}$. The reductive elimination of cobalt carbonyl residue $\left(\mathrm{Co}_{2}(\mathrm{CO})_{5}\right)$ of $\mathbf{D}$ leads to form the major diastereoisomer of 10a.

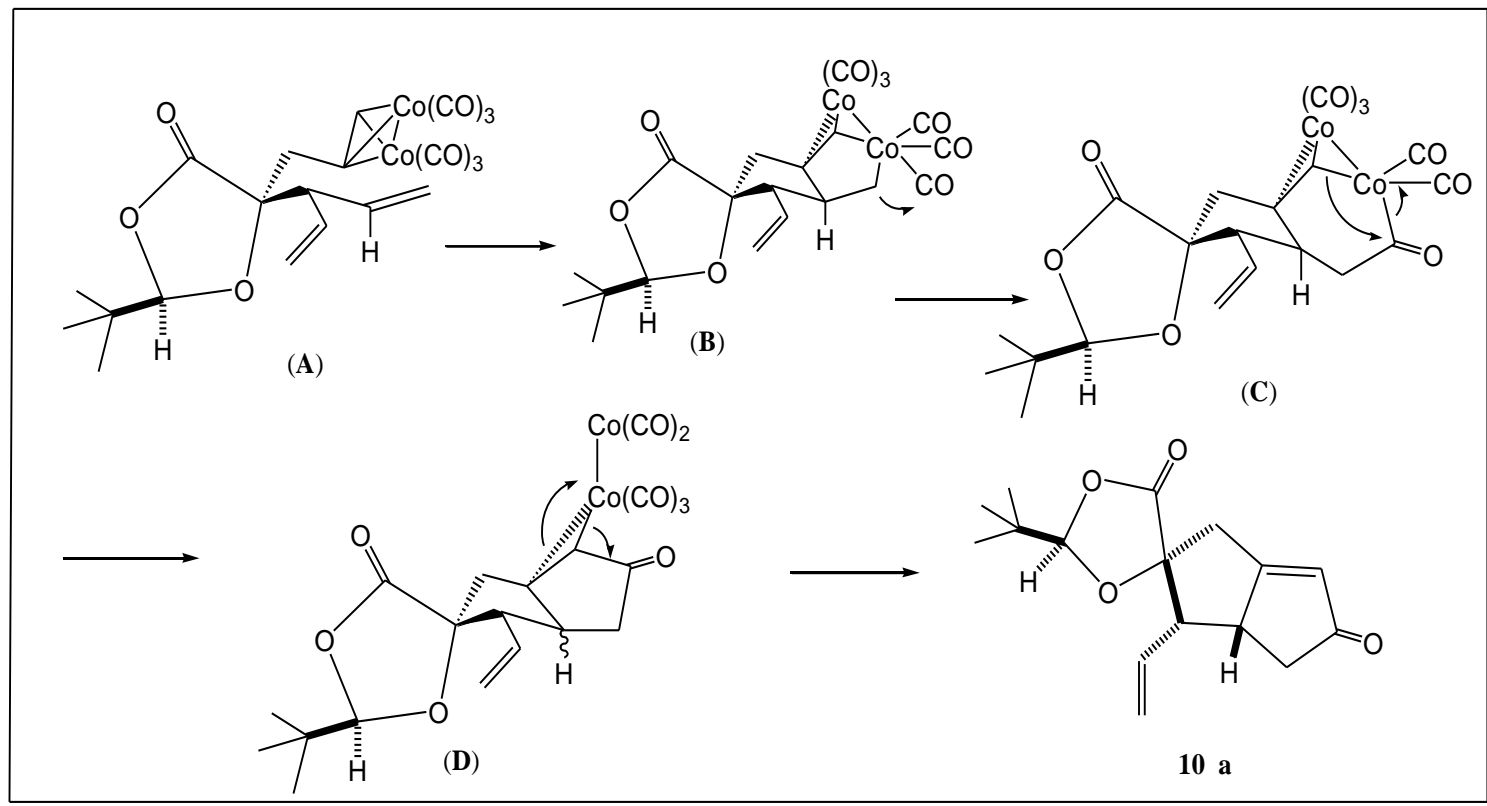

Figure 8: Proposed mechanism for intramolecular Pauson-Khand reaction

\subsection{CONCLUSION}

We have documented here highly functionalized stereo selective and efficient synthesis of five-membered bicyclic 1- hydroxycarboxylic acid derivatives based on PausonKhand cyclization. As 1-hydroxycycloalkane-1-carboxylic acids serve as important staring compounds for the preparation of biologically active molecules, this method can be applied in the synthesis of wide range of biologically relevant molecules.

\subsection{ACKNOWLEDGEMENT}

Author is thankful to Swiss National Science foundation and Swiss Federal Commission of Scholarships for providing financial support for this research and to Professor Philippe Renaud, University of Bern, Switzerland for his valuable guidance for the research. 


\subsection{REFERENCES}

[1]. Barco, A., Benetti, S., De, Risi, C., Machetti, P., Pollini, G, P., and Zanirato, V. (1997). D-(-)-Quinic acid: a chiron store for natural product synthesis, Tetrahedron asymmetry 8 (21): 3515-3545.

[2]. Dochnahl, M., and Geogery, C, Fu. (2009). Catalytic Asymmetric Cycloaddition of Ketenes and Nitroso Compounds: Enantioselective Synthesis of $\alpha$ Hydroxycarboxylic Acid Derivatives. Angewantte Chemistry International Edition English 48(13): 2391-2393.

[3] Abazi, S., Parra, Rapado, L., Schenik, K., and Renaud, P. (1999). Preparation of 1-Hydroxycyclopentanecarboxylic Acid Derivatives from a Chiral Equivalent of Glycolic Acid. European Journal of Organic Chemistry (2): 477-483.

[4]. Rapado, L, P., Bulugahapitiya, V., and Renaud, P. (2000). Synthesis of NonRacemic 1-Hydroxycycloalkene-1-carboxylic-Acid derivatives by Metathesis of $\alpha, \alpha-$ Dialkylated Glycolate Derivatives. Helvetica Chimica Acta 83(7): 1625-1632.

[5] Bulugahapitiya, V, P., and Renaud, P. (2001). Polysubstituted 1hydroxycyclopentane carboxylic acid derivatives via group-selective radical annulations. C.R. Academic Science Paris, Chimie/Chemistry 4: 619-624.

[6]. Peter, L, P. (1985). The Khand reaction: A convenient and general route to a wide range of cyclopentenone derivatives. Tetrahedron 41(24): 5855-5860.

[7]. Hook, J, M. (1984). A simple and efficient synthesis of ethyl and methyl glyoxylate. Synthetic Communication 14: 83-87.

[8]. Jung, M, E. and Nicolas, C, J. (1996). Stereo selective synthesis of trans, trans-4aryl-2, 3-oxetanedimethanols: Preparation of oxetanocin a analogues. Tetrahedron Letters 37: 7667-7670. 
[9]. Tormo, J., Moyomo, A., Pricas, M, A., and Riera, A. (1997). Enantioselective Construction of Angular Triquinanes through an Asymmetric Intramolecular PausonKhand Reaction. Synthesis of (+)-15-Nor-pentalenene. Journal of Organic Chemistry 62 (14): 4851-4856.

[10]. Seebach, D., Naef, R., and Calderari, G. (1984). $\alpha$-Alkylation of $\alpha$ heterosubstituted carboxylic acids without racemization: EPC-syntheses of tertiary alcohols and thiols. Tetrahedron, 40 (8): 1313-1324.

\subsection{APPENDIX}

\subsection{Detail experimental part and spectroscopic data of the compounds}

Ethyl 3-ethenyl-2-hydroxypent-4-enoate (7): A solution of 5-bromopenta-1,3-diene $(2.0 \mathrm{~g}, 13.6 \mathrm{mmol})$ in THF $(5 \mathrm{ml})$ was added to a suspension of $\mathrm{Zn}(890 \mathrm{mg}, 13.6$ mmol) and $\mathrm{AlCl}_{3}(1.8 \mathrm{~g}, 13.6 \mathrm{mmol})$ in THF $(32 \mathrm{ml})$ at room temperature under $\mathrm{N}_{2}$. After stirring for $15 \mathrm{~min}$, a solution of ethyl glyoxylate $(1.38 \mathrm{~g}, 13.86 \mathrm{mmol})$ in THF $(5.0 \mathrm{ml})$ was added and the mixture was stirred for $8 \mathrm{hrs}$ until all starting compound was consumed. Then the mixture was poured into sat. $\mathrm{NH}_{4} \mathrm{Cl}$ solution $(10.0 \mathrm{ml})$ and extracted with $\mathrm{Et}_{2} \mathrm{O}$ ( $3 \times 40 \mathrm{ml}$ ). The combined organic phase was washed with brine, dried with $\mathrm{MgSO}_{4}$ and evaporated, and crude product was purified by $\mathrm{FC}$ (hexane/AcOEt 4:1); compound 7 afforded pale yellow oil, $1.20 \mathrm{~g}, 52 \%$ yield. IR (Film): 3501, 3080, 2982, 2937, 2936, 1737, 1250, 1109. ${ }^{1} \mathrm{H}-\mathrm{NMR}(360 \mathrm{MHz}): \delta=$ 5.78-5.71 (m, $2 \mathrm{H}, 2 \mathrm{CH}=\mathrm{CH}_{2} ; 5.11-4.95\left(\mathrm{~m}, 4 \mathrm{H}, 2 \mathrm{CH}=\mathrm{CH}_{2}\right) ; 4.2(\mathrm{~m}, 3 \mathrm{H}, \mathrm{CHOH}$, $\left.\mathrm{MeCH}_{2} \mathrm{O}\right) ; 4.15(d, 1 \mathrm{H}, \mathrm{OH}) ; 3.68-3.51\left(m, 1 \mathrm{H}, \mathrm{CH}\left(\mathrm{CH}-\mathrm{CH}_{2}\right)_{2}\right) ; 1.27\left(t, 3 \mathrm{H}, \mathrm{MeCH}_{2} \mathrm{O}\right)$. ${ }^{13} \mathrm{C}-\mathrm{NMR}(50.3 \mathrm{MHz}) ; \quad 173.42(\mathrm{~s}) ; \quad 136.48(\mathrm{~s}) ; \quad 111.91(\mathrm{~s}) ; \quad 80.54(\mathrm{~s}) ; \quad 61.59(\mathrm{~s}) ;$ 41.5(s),14.2(s). CI-MS: 171(4, $\{\mathrm{M}+1\}^{+}, 170\left(36, \mathrm{M}^{+}\right), 152(11), 151(5), 142(3), 124(14)$, 123(8), 122(5), 106(10), 102(6), 96(35), 80(12), 78(30), 77(7), 68(27), 67(54), 66(100), 54(24), Anal. Cal. for $\mathrm{C}_{9} \mathrm{H}_{14} \mathrm{O}_{3}(170.21)$ : C 63.51, H 8.29; Found C 62.95, H 7.99.

2-(tert-butyl)-5-(1-ethenylprop-2-enyl)-1,3-dixololan-4-one (8): A mixture of 7 (2.0 $\mathrm{g}, 11.6 \mathrm{mmol}), 2.2$-dimethylpropanal $(4.0 \mathrm{~g}, 94.08 \mathrm{mmol})$, TsOH $(950 \mathrm{mg})$, and 1 drop of conc. $\mathrm{H}_{2} \mathrm{SO}_{4}$ in pentane $(20 \mathrm{ml})$ was heated under reflux with azeotropic removal of $\mathrm{H}_{2} \mathrm{O}$. After completion of the reaction, the solution was washed with $\mathrm{H}_{2} \mathrm{O}$, dried with $\mathrm{MgSO}_{4}$ and evaporated under vaccum. The crude product was purified by FC (pentane: $\mathrm{Et}_{2} \mathrm{O}$ 20:1) gave cis:trans mixture of 8 in 1:1 (1.60 g, $65 \%$ ). IR (Film): 3583, 3084, 2976, 2910, 2876, 1788, 1485, 1363, 1201, 1103. CI-MS: 211(42, $\left.[\mathrm{M}+1]^{+}\right), 194(7)$, 
193(57), 189(4), 183(9), 175(8), 171(19), 167(7), 166(27), 152(25). HR-MS: 211.1326 $\left(\mathrm{C}_{12} \mathrm{H}_{19} \mathrm{O}_{3}\right)^{+},[\mathrm{M}+1]^{+}$; calc. 211.1328 .

Trans-8: ${ }^{1} \mathrm{H}-\mathrm{NMR}(500 \mathrm{MHz}): \delta=5.97-5.83\left(m, 2 \mathrm{H}, 2 \mathrm{CH}=\mathrm{CH}_{2}\right) ; 5.27-5.25(m, 5 \mathrm{H}, \mathrm{H}-$ $\left.\mathrm{C}(2), 2 \quad \mathrm{CH}=\mathrm{CH}_{2}\right) ; \quad 4.45-4.44(d d, \mathrm{~J}=3.35, \quad 1.6,1 \mathrm{H}, \quad H-\mathrm{C}(5)) ; 3.31-3.25(m, 1 \mathrm{H}$, $\left.\mathrm{CH}\left(\mathrm{CH}=\mathrm{CH}_{2}\right)_{2}\right) ; 0.94\left(\mathrm{~s}, 9 \mathrm{H}, t\right.$-Bu). ${ }^{13} \mathrm{C}-\mathrm{NMR}(126.76 \mathrm{MHz}): 172(\mathrm{~s}) ; 135.4(\mathrm{~s}) ; 132.4(\mathrm{~s}) ;$ $119.2(\mathrm{~s}) ; 118.1(\mathrm{~s}) ; 111.4(\mathrm{~s}) ; 78.1(\mathrm{~s}) ; 50.3(\mathrm{~s}) ; 23.1(\mathrm{~s})$.

2-tert-butyl-5-(2-propenyl)-5(1-vinyl-2-propenyl)-1,3-dioxolan-4-one (9): To a solution of LDA $(4.2 \mathrm{ml}, 4.2 \mathrm{mmol})$ at $-78^{\circ} \mathrm{C}$. a solution of trans-8 $(740 \mathrm{mg}, 3.52$ $\mathrm{mmol})$ in THF $(2.0 \mathrm{ml})$ was added slowly and stirred for $5 \mathrm{~min}$. A solution of propagyl bromide (2.096 g, $17.6 \mathrm{mmol})$ in THF $(2.0 \mathrm{ml})$ was added and the solution was allowed to warm up to r.t. After about $2 \mathrm{hrs}$, saturated solution of $\mathrm{NH}_{4} \mathrm{Cl}$ was added and the solution was extracted with $\mathrm{Et}_{2} \mathrm{O}(3 \times 20 \mathrm{ml})$. combined organic phases was washed with brine and dried over $\mathrm{MgSO}_{4}$. After evaporation of the solvent the crude was purified by FC (hexane/EtOAc, 20:1), 9 afforded as pale yellow oil and as single isomer, $560.00 \mathrm{mg}, 65 \%$. IR (Film): 3620; 3296; 3084; 2976; 2876; 2360; 1797; 1485; 1410; 1195. ${ }^{1} \mathrm{H}-\mathrm{NMR}(500 \mathrm{MHz}): \delta=5.92-5.79\left(\mathrm{~m}, 2 \mathrm{H}, 2 \mathrm{CH}=\mathrm{CH}_{2}\right) ; 5.9(s, 1 \mathrm{H}, \mathrm{HC}-\mathrm{t}-$ $\mathrm{Bu}) ; 5.28-5.12(m, 4 \mathrm{H}, 2 \mathrm{CH}=\mathrm{CHH}) ; 3.2\left(m, 1 \mathrm{H}, \mathrm{CH}\left(\mathrm{CH}=\mathrm{CH}_{2}\right)_{2}\right) ; 2.75-2.7(d d, 1 \mathrm{H}$, $\mathrm{J}=17.13,2.67, H \mathrm{HC}-\mathrm{CCH}) ; 2.69-2.59(d d, 1 \mathrm{H}, \mathrm{J}=17.63,2.67, \mathrm{HHC}-\mathrm{CCH}) ; 2.09(t, 1 \mathrm{H}$, $\left.\mathrm{J}=2.74 \mathrm{CH}_{2} \mathrm{CCH}\right) ; 1.0(s, 9 \mathrm{H}, \mathrm{t}-\mathrm{Bu}) .{ }^{13} \mathrm{C}-\mathrm{NMR}(125.7 \mathrm{MHz}): 173.06(\mathrm{~s}), 134.9(\mathrm{~s})$, 133.9(s), 120.15(s), 119.2(s), 109.83(s), 83.7(s), 78.3(s), 72.3(s), 53.7(s), 34.9(s), 24.7(s), 24.27(s). CI-MS: 249(8, [M+1]+), 209(5), 202(6), 190 (7), 180 (9), 162 (19), 152 (7), 137 (13), 136 (100), 134 (22), 118 (8),116 (6),108 (23), 106 (17), 94 (19), 80 (27),66 (44), 56 (13). Anal.calc. for $\mathrm{C}_{15} \mathrm{H}_{20} \mathrm{O}_{3}$ (248.322): C 72.55, $\mathrm{H}$ 8.12: found: $\mathrm{C}$ 72.63, H 8.00 .

\section{7-[2-tert-butyl)-6-vinyl-1,3'-dioxolan-4noyl]-bicyclo [3.3.0] oct-1-en-3-one (10a): To} a solution of $9(120 \mathrm{mg}, 0.48 \mathrm{mmol})$ in $\mathrm{Et}_{2} \mathrm{O}(2.0 \mathrm{ml})$, dicoboltoctacarbonyl $(198 \mathrm{mg}$, $0.58 \mathrm{mmol}$ ) was added and stirred at room temperature. After completion of the complex (about $2 \mathrm{hrs}$ ), $\mathrm{Et}_{2} \mathrm{O}$ was evaporated and pure alkyne-cobalt complex (220 mg, $77 \%$ ) was obtained after FC (hexane: EtOAc, 20:1). To this cobalt complex in $\mathrm{CH}_{2} \mathrm{Cl}_{2}$ $(10 \mathrm{ml}), \mathrm{NMO}^{\mathrm{H}} \mathrm{H}_{2} \mathrm{O}(654 \mathrm{mg}, 4.8 \mathrm{mmol})$ was added and stirred for $5 \mathrm{hrs}$ at r.t. The solution was dried with $\mathrm{MgSO}_{4}$ and followed by filtration, and the crude product obtained was purified using FC (hexane: EtOAc. 2:1) to afford mixture of products, 10 $\mathbf{a}$ and $\mathbf{1 0} \mathbf{b}(76 \% d s, \mathrm{GC})$. The two diastereomers in the mixture was separated by preparative HPLC. Major (10 a); ${ }^{1} \mathrm{H}-\mathrm{NMR}(360 \mathrm{MHz}) ; \delta=6.0\left(m, 1 \mathrm{H}, H \mathrm{C}=\mathrm{CCH}_{2}\right)$; 5.9-5.8( $\left.m, 1 \mathrm{H}, \mathrm{HC}=\mathrm{CH}_{2}\right) ; 5.29-5.23(m, 2 \mathrm{H}, \mathrm{CH}=\mathrm{CHH}) ; 5.1(s, 1 \mathrm{H}, \mathrm{HC}-\mathrm{t}-\mathrm{Bu}) ; 3.4(m$, 
$\left.1 \mathrm{H}, \mathrm{CH}-H \mathrm{C}-\mathrm{CH}_{2}\right) ; 3.2(d, 1 \mathrm{H}, \mathrm{J}=18.31, H \mathrm{HC}-\mathrm{C}=\mathrm{CH}) ; 2.9(d, 1 \mathrm{H}, \mathrm{J}=18.31, \mathrm{H} H \mathrm{C}-$ $\mathrm{C}=\mathrm{CH}) ; 2.6(d d, \mathrm{~J}=18.31,6.72, H \mathrm{HC}-\mathrm{CO}) ; 2.5\left(d d, 1 \mathrm{H}, \mathrm{J}=12.51,8.24, H \mathrm{C}-\mathrm{HC}=\mathrm{CH}_{2}\right)$; $2.1(d d, 1 \mathrm{H}, \mathrm{J}=18.3,3.05, \mathrm{HHC}-\mathrm{CO}) 1.0(\mathrm{~s}, 9 \mathrm{H}, t-\mathrm{Bu}) .{ }^{13} \mathrm{C}-\mathrm{NMR}(125,7 \mathrm{MHz})$ : 208.8(s); 181.5 (s); 174.0(s); 133.2 (s); 126.9 (s); 121.1 (s); 106.9 (s); 87.8 (s); 66.1 (s); 57.1 (s), 48.5 (s), 34.7 (s), 32.1(s); 25.9 (s). IR (KBr): 2949; 2948; 2897; 2348; 2344; 2281; 1776; 1685; 1641; 1640; 1529; 1210; 1111; 1110; 962; 970. CI-MS: 278 (21 $\left.[\mathrm{M}+1]^{+}\right) ; 277$ (91); 259 (9); 241 (3); 230 (6); 219 (20); 204(3); 191 (9); 190 (100); 189 (16); 188 (4); 172 (3); 162 (55); 161 (7); 144 (9); 86 (6). Anal calc. for $\mathrm{C}_{16} \mathrm{H}_{20} \mathrm{O}_{4}$ (276.33) C 69.55, H 7.30: found C 69.65, H 7.33. 